\title{
Vitamins and Nutraceuticals from the Perspective of Process Research
}

\author{
Thomas Netscher* \\ SISF-SCS Senior Industrial Investigator Award 2017
}

\begin{abstract}
The development of efficient, sustainable low-cost processes is the basis for providing high-quality products for daily life applications in human and animal nutrition. In this account, the importance of chemical process research towards ecologically benign and competitively advantageous processes for the large-scale preparation of various vitamins, nutraceuticals and fine chemicals is highlighted. Selected and representative examples are given, including contributions from collaborations with external partners. General trends include the shift from stoichiometric to catalytic protocols and from batch to continuous processes. In addition, the use of renewable (bio-based) raw materials as an alternative to access key building blocks for the production of vitamins is addressed.
\end{abstract}

Keywords: Asymmetric catalysis · Isoprenoids · Nutrition · Renewables · Stereochemistry

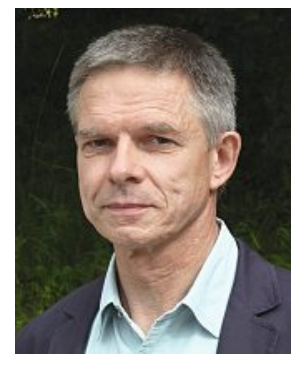

Thomas Netscher studied chemistry at the Universities of Constance and Freiburg i.Br., Germany, working with Horst Prinzbach during his diploma and doctoral theses on the synthesis of polyolefins, inosites, complex ligands, and reagents for substitution reactions. In 1987 he started in the Vitamins and Fine Chemicals Division of F. Hoffmann-La Roche, now DSM Nutritional Products, in Basel (with a stay at the Roche Research Center in Nutley, New Jersey, USA in 1991/92) where he is

currently a Principal Scientist responsible for isoprenoid chemistry. Together with colleagues from DSM and Solvias he received the Sandmeyer Award of the Swiss Chemical Society in 2008, held the Roche Lecture at 25 European universities and research institutions in 1997/98, and served as a Lehrbeauftragter in organic chemistry at the University of Freiburg i.Br.. He is a member of the German, the Swiss, and the American Chemical Societies. The considerable interest directed towards co-operations of academia with industry resulted in many joint research projects documented within the around 200 patents and publications.

\section{Introduction}

Vitamins and nutraceuticals are produced on an industrial scale by total or partial chemical synthesis, by isolation (mainly extraction) from material of natural origin, by fermentation, or by a combination of such methods. Many vitamins have become large-scale products for various applications in human and animal nutrition due to a constantly increasing demand. Efficient production methods are, therefore, needed to ensure a proper supply of materials in terms of quantity and quality. The examples given in this short review describe the role of a chemist in the field of vitamins and nutraceuticals from a viewpoint of process research, ${ }^{[1]}$ i.e. find solutions for improving existing process steps, searching for new concepts, developing alternative and better synthetic routes, and, not forgetting assisting if problems in production pop up. And, moreover, process research has to take responsibility for moving towards environmentally more benign protocols and sustainable processes.

\section{Examples from the Field of Vitamins}

The first vitamin, thiamine (vitamin $\mathrm{B}_{1}$ ) was discovered more than hundred years ago. In close collaboration with Swiss academia, L-ascorbic acid (vitamin C) was the first vitamin prepared on a technical scale by F. Hoffmann-La Roche in Basel (Fig. 1). ${ }^{[1 a]}$ All thirteen vitamins are industrially produced today, most of them by chemical synthesis, and considered fine chemicals with production volumes of about 100 to 10 '000 tons per year.

\subsection{Vitamin E - Industrial Production}

(all-rac)- $\alpha$-Tocopherol ((all-rac)-3, Scheme 1) is the industrially most important lipid-soluble antioxidant which is manufactured on a scale of $>35^{\prime} 000$ tons per year. All producers (i.e. DSM Nutritional Products in Switzerland, BASF in Germany and some Chinese companies) complete the synthesis by a condensation reaction of the aromatic building block a

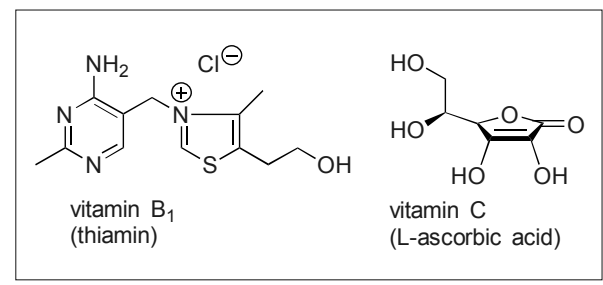

Fig. 1. First vitamins discovered and prepared on a technical scale. 


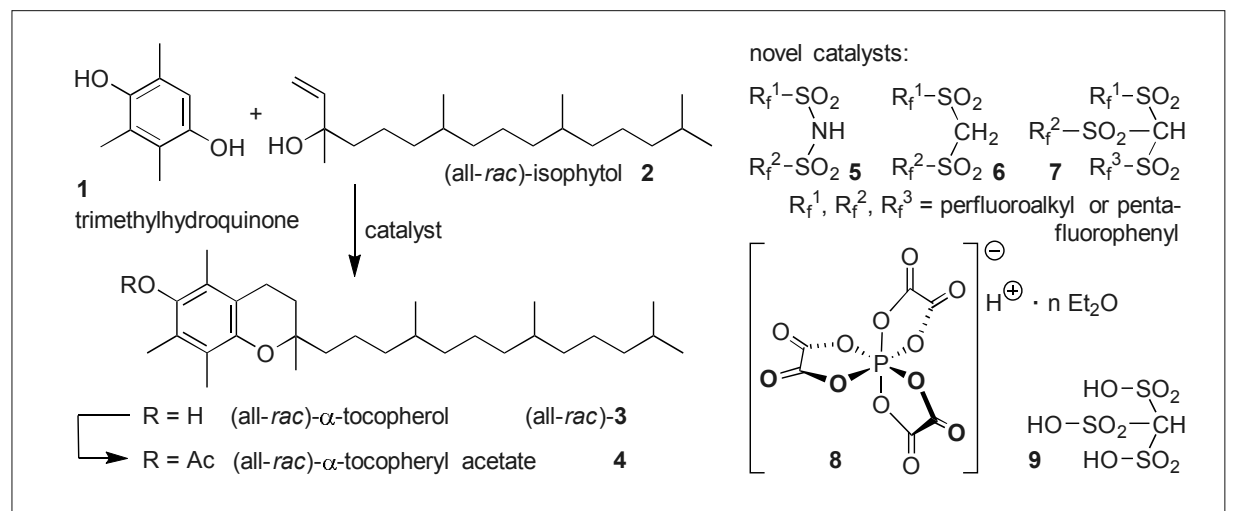

Scheme 1. Acid-catalyzed synthesis of (all-rac)- $\alpha$-tocopherol.

trimethylhydroquinone (1) with the $\mathrm{C}_{20}$ isoprenoid isophytol (2). The acetate derivative $\mathbf{4}$ is the main application form going to animal nutrition. Conventional reaction conditions for the condensation reaction (Scheme 1) involve the use of a strong Brønsted acid (e.g. hydrochloric acid) and/or a Lewis acid, such as zinc chloride, which gives rise to problems with selectivity (formation of by-products and waste) and corrosion. We have, therefore, investigated a series of new catalysts and alternative procedures, e.g. by using biphasic solvent systems. Beside other novel catalysts, ${ }^{[1]]}$ strongly acidic perfluorinated imides $\mathbf{5}^{[2]}$ and methides $\mathbf{6}$ and $\mathbf{7}^{[3]}$ applied in true catalytic amounts delivered superior results. Other exceptionally active acidic catalysts were phosphorus acid $\mathbf{8}^{[4]}$ and methanetrissulfonic acid $\mathbf{9}^{[5]}$ which gave excellent results also in other transformations such as acylation and WagnerMeerwein rearrangement reactions.

The key building block isophytol (2, Scheme 2) can be accessed by various approaches. One basic principle is the combination of $\mathrm{C}_{2}$ and $\mathrm{C}_{3}$ elongation reactions, starting e.g. from acetylene and acetone or an activated derivative isopropenyl methyl ether (10). Key transformations are Carroll or Saucy-Marbet, ethynylation, Lindlartype semihydrogenation, and total hydrogenation reactions. ${ }^{[1 \mathrm{~d}, \mathrm{e}]}$ The intermediate pseudoionone (11) can either be processed further to isophytol (towards vitamin $\mathrm{E}$ ) or fed into the preparation of vitamin A.

\subsection{Vitamin E - Stereoisomers, Asymmetric Catalysis and Total Synthesis}

In addition to its role as an antioxidant, vitamin $E$ has a specific biological activity which has been investigated in animal and in vitro experiments. ${ }^{[6]}$ Although all stereoisomers and homologues show qualitatively the same effect, they differ quantitatively depending on their substitution pattern. Naturally occurring vitamin E compounds are all single-isomer substituted 6-chromanols (Fig. 2). (2R, $\left.4^{\prime} R, 8^{\prime} R\right)$ $\alpha$-tocopherol $(R R R-3)$ is the most active one. Vitamin E compounds with unsaturated aliphatic side chain (tocotrienols 15, e.g. $\left(2 R, 3^{\prime} E, 7^{\prime} E\right)-\alpha$-tocotrienol $R E E$ 16) are also found in nature. For applications in the pharmaceutical, food, and cosmetics industry, $R R R-3$ is prepared by a semi-synthetic route: A mixture of $\alpha-, \beta-$, $\gamma$ - and $\delta$-tocopherol homologues $(R R R-3$ and $R R R-12$ to -14) is extracted from a waste stream of soybean production, and further transformed chemically by permethylation to $R R R-\mathbf{3}$, thus upgrading the value of the product. The amount obtained by this approach covers, however, only $c a$. $10 \%$ of the total worldwide demand for vitamin $\mathrm{E}$, due to limited availability of resources.

There is, therefore, the need for an economic stereoselective total synthesis, and considerable efforts have been directed towards suitable methodologies. ${ }^{[6]}$ Based on the seminal work of Noyori and oth$\mathrm{C}_{10}$ and $\mathrm{C}_{15}$ isoprenoid alcohols $\mathbf{1 7}$ and $\mathbf{2 0}$ could be performed at Roche on kilogram scale by applying the ruthenium-catalyzed asymmetric hydrogenation of allyl alcohols (Scheme 3). In this sequence, purification and isolation of substrate $E \mathbf{- 1 8}$ / $E-19$ became a major challenge. ${ }^{[7]}$ Another issue was analytics of the intermediates obtained: The reliable quantification of ers, the highly stereoselective synthesis of

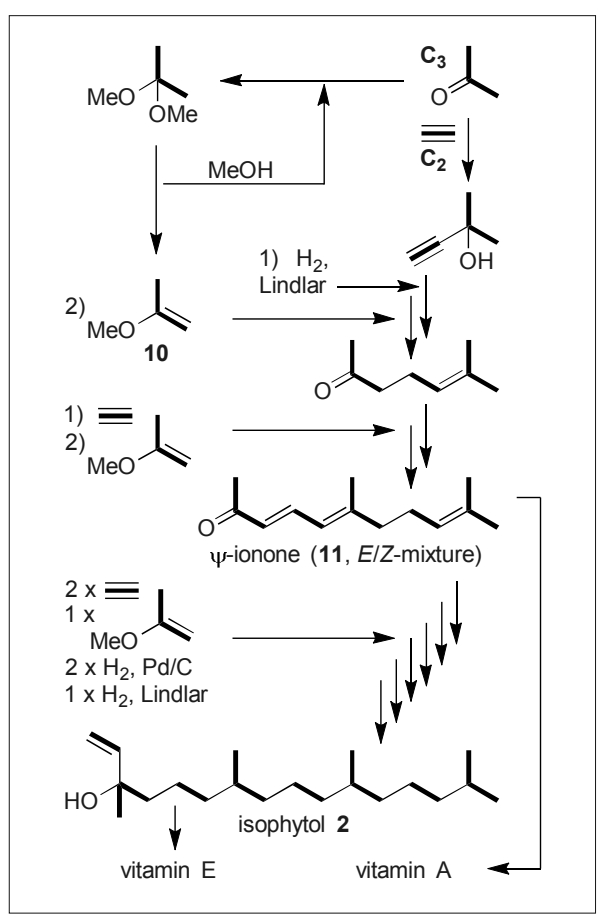

Scheme 2. Synthesis of isophytol $\left(C_{20}\right.$ sidechain).

stereoisomers could be achieved by derivatization to tartrate acetals of type 21 / 22 and their separation on home-made $100 \mathrm{~m}$ (!) GC capillary columns (Fig. 3). ${ }^{[8]}$ The synthesis and stereochemical analysis of chiral isoprenoid building blocks in our laboratories have been reviewed ${ }^{[9]}$ and was the topic of the 'Roche Lecture' given by the author in 1997/98. ${ }^{[10]}$

At this point, a special remark has to be made. Michelangelo Scalone from Process Research, Roche Basel, received the "KGF-SCS Senior Industrial Science Award 2015 for his outstanding contributions to the design of new, short and costefficient syntheses for many development projects by applying asymmetric catalytic reactions". ${ }^{[11]}$ During his award lecture in Lausanne, he presented the slide shown in Fig. 4, representing six chiral biologically active compounds from the area of

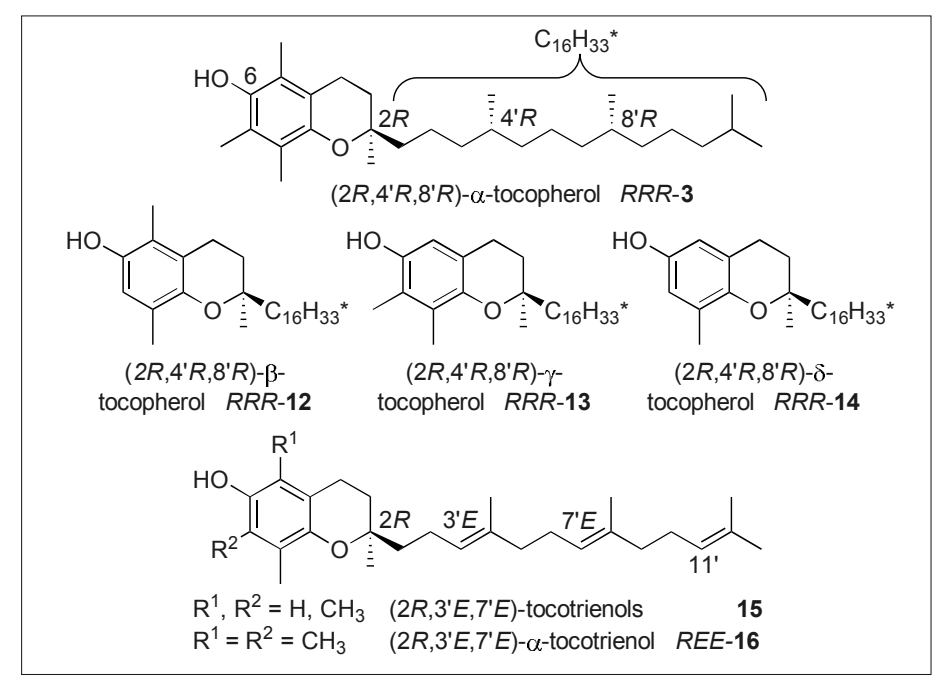

Fig. 2. Structures of naturally occurring tocopherols and tocotrienols. 
vitamins, carotenoids and fine chemicals that belonged to the targets of process R\&D activities at Roche on homogeneous catalysis with metal complexes around the year 1990.[13]

The way to completely different retrosynthetic concepts was opened by the breakthrough in asymmetric catalysis achieved in the Pfaltz group. The concomitant introduction of two chiral centers became possible by the use of iridium-BAr ${ }_{F}$ complexes containing P,N ligands such as 25 in asymmetric hydrogenation of unfunctionalized trialkyl substituted olefins (Scheme 4). Highly valuable examples are the reduction of (all-E)-farnesol (23) ${ }^{[14]}$ and of (all-E)-tocotrienol derivative $\mathbf{2 4}$ to tocopherol derivative 26. ${ }^{[15]}$ The tocotrienol used as the starting material (as well as other homologues and stereoisomers, e.g. $\left(2 R, 3^{\prime} E, 7^{\prime} E\right)$ - $\alpha$-tocotrienol, $\left.R E E-16\right)$ was synthesized by the sequence depicted in Scheme 5. ${ }^{[16]}$ The asymmetric hydrogenation of isoprenoid olefins could be further improved with regard to activity and selectivity of the catalyst by the use of special solvents and Lewis acids. [17]

In an approach based on the biosynthetic pathway of tocopherols, the mechanism of the enzymatic chromanol-ring formation was investigated in the group of Woggon (Scheme 6). By independent synthesis of labelled reference material, the stereospecific course of the reaction could be identified. ${ }^{[18]}$

Two total syntheses of $\left(2 R, 4^{\prime} R, 8^{\prime} R\right)-\alpha-$ tocopherol $(R R R-3)$ were elaborated by applying chiral metal complexes as catalysts. In a $\mathrm{Rh}$-catalyzed hydroformylation followed by an allylic substitution reaction, a reagent-directing group served to control the stereoselectivity (Scheme 7). [19] High stereoselectivity for the formation of the chiral chroman center could be achieved by a $\mathrm{Cu}$-mediated asymmetric 1,4-addition with a commercially available catalyst (Scheme 8). [20] The presence of an activating group is, however, mandatory.

In 1978, Kabbe and Heitzer had published an achiral organocatalytic approach to chromans. ${ }^{[21]}$ 4-Oxo-tocotrienol (28) was accessible in good yield using 2-acetyl-trimethylhydroquinone (29) and farnesyl acetone (27) as starting materials (Scheme 9). The idea of replacing pyrrolidine as a base by a chiral organocatalyst turned out to be rather difficult to accomplish. Many stateof-the-art organocatalysts (e.g. Jørgensen, MacMillan type) were revealed to be unsuitable for this transformation. In a broad screening, mostly no conversion or racemic products were observed. Successful examples with moderate selectivity (d.r. $=63: 37)$ could be obtained by applying certain substituted pyrrolidine derivatives. The presence of Brønsted acidic compounds plays an important role. ${ }^{[22]}$

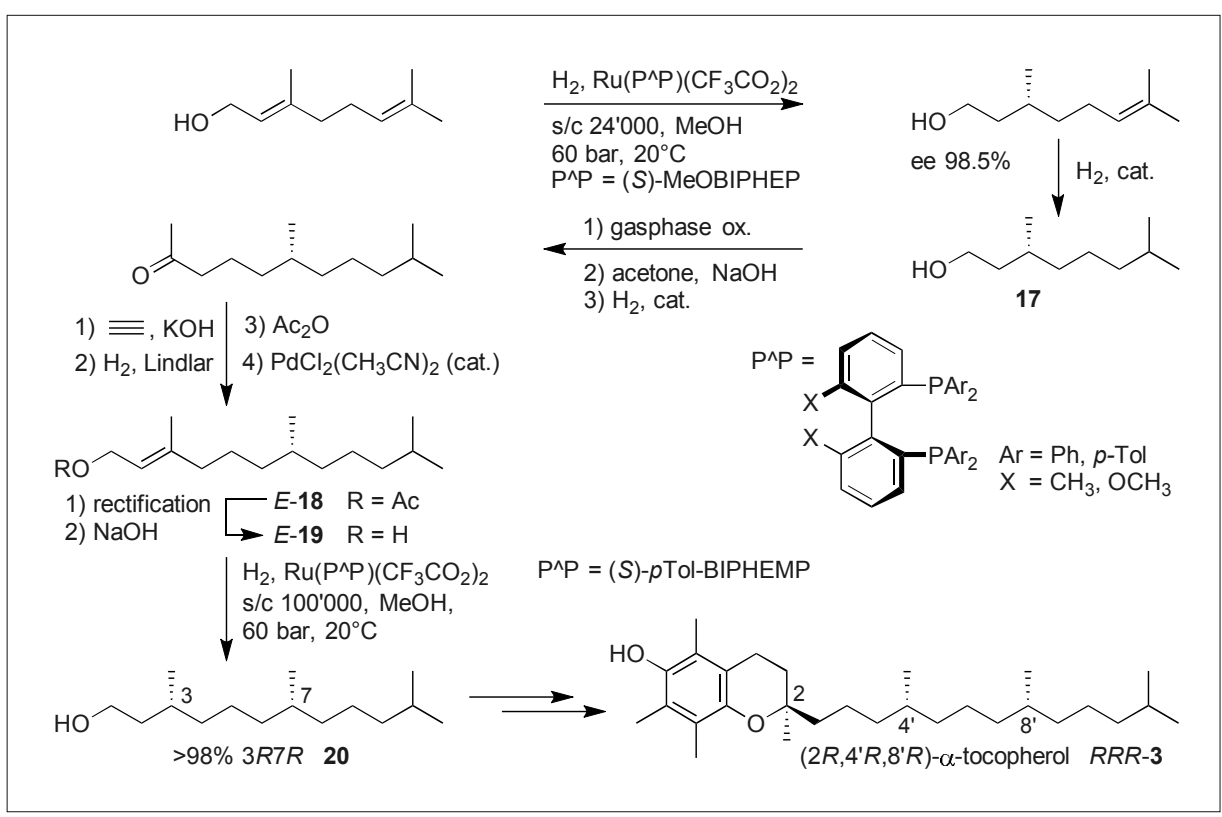

Scheme 3. Pilot scale synthesis of chiral isoprenoid side-chain intermediates.

\subsection{Vitamin E-Alternative Access to \\ Key Building Blocks}

Trimethylhydroquinone (1), the aromatic building block for the condensation reaction to (all-rac)- $\alpha$-tocopherol $(\mathbf{3}$, $c f$. Scheme 1), is mainly accessed from $m$-cresol (Scheme 10) by a methylationoxidation-hydrogenation sequence. In order to avoid shortage on $m$-cresol, several other routes have been evaluated. A more easily available starting material is acetone which is trimerized to isophorone and transformed by allylic oxidation to ketoisophorone (KIP). The acid-catalyzed Wagner-Meerwein rearrangement delivers trimethylhydroquinone diacetate. Both routes, however, use fossil sources. In or-

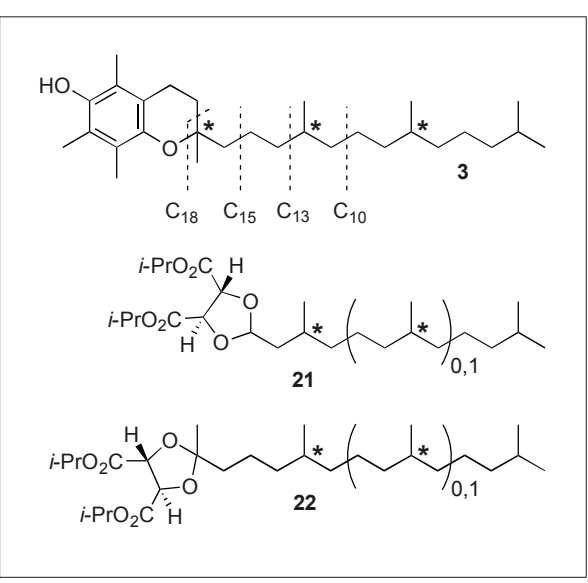

Fig. 3. Stereochemical analysis of chiral sidechain building blocks.

\section{Roche Chiral Challenges in the 80ies}
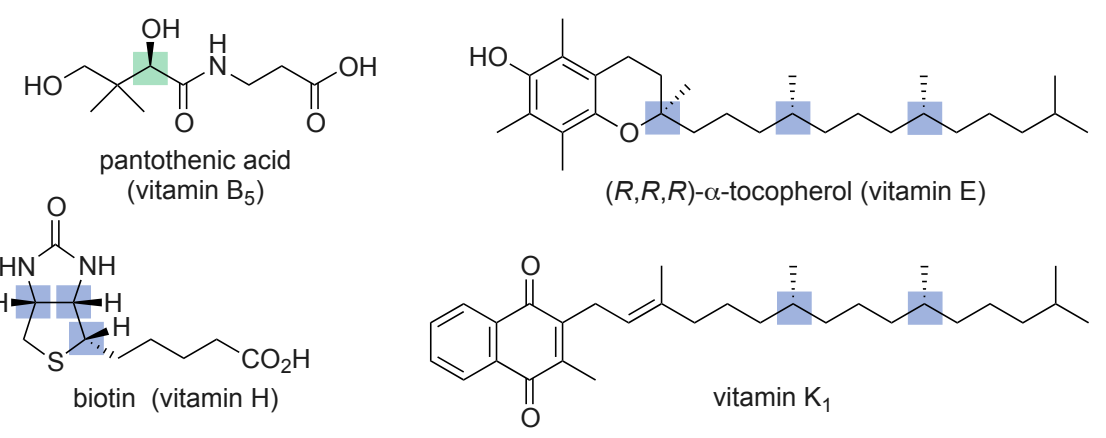

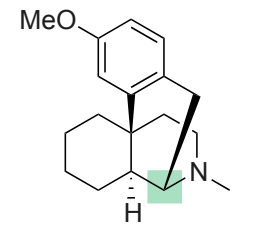

dextromethorphan (cough suppressant)<smiles>CC1=C(/C=C/C(C)=C/C=C/C(C)=C/C=C/C=C(C)/C=C/C=C(C)/C=C/C2=C(C)C[C@H](O)CC2(C)C)C(C)(C)C[C@H](O)C1</smiles>
(carotenoid; corn)

Fig. 4. 'Roche Chiral Challenges in the 1980s' (courtesy of Michelangelo Scalone, Process Research \& Development, Pharmaceuticals Division, F. Hoffmann-La Roche, Basel). ${ }^{[12]}$ 


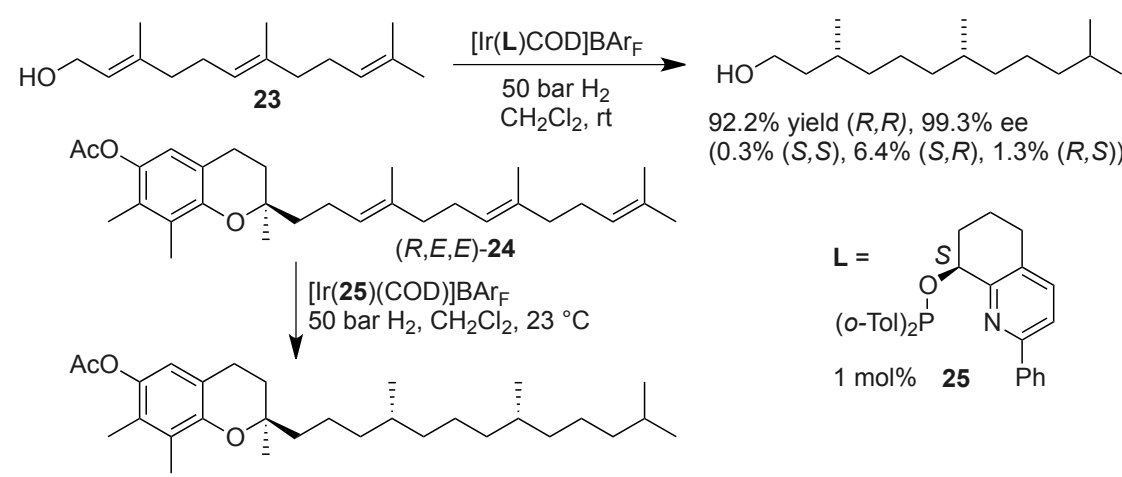

$\left(2 R, 4^{\prime} R, 8^{\prime} R\right)$ - $\gamma$-tocopheryl acetate 26 ( $\left.>98 \% R R R,<0.5 \% R R S,<0.5 \% R S R,<0.5 \% R S S\right)$

Scheme 4. Iridium-catalyzed asymmetric hydrogenation of trialkyl-substituted $\mathrm{C}=\mathrm{C}$ bonds.

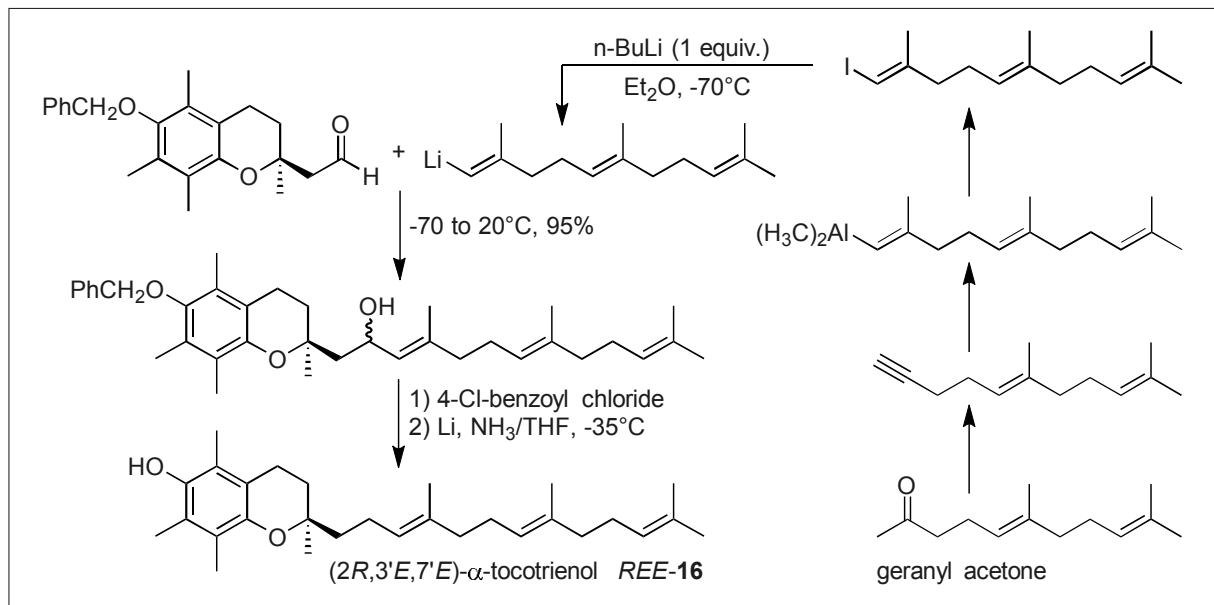

Scheme 5. Synthesis of $(R, E, E)$-tocotrienols.

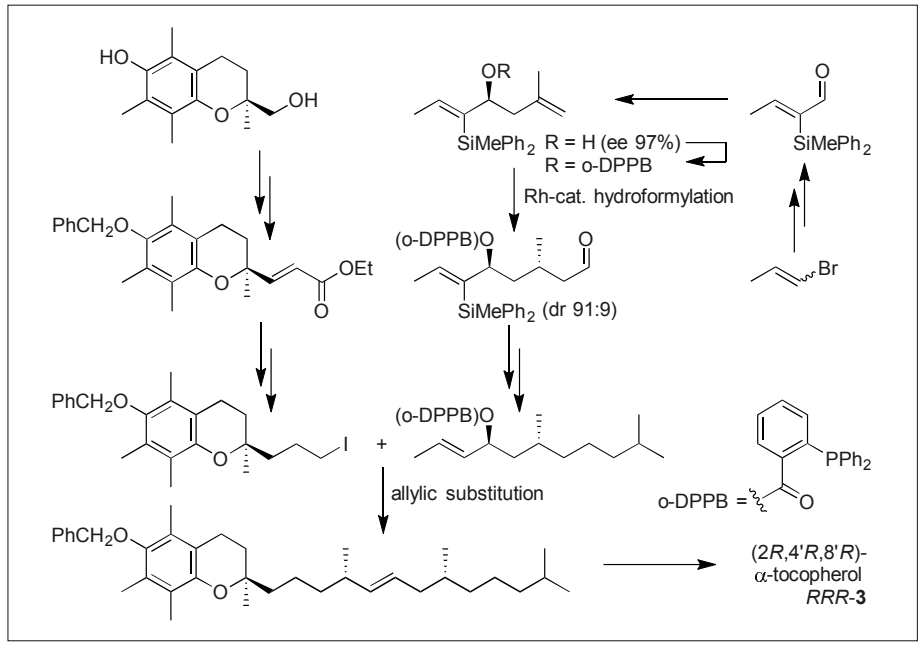

Scheme 7. A hydroformylationallylic substitution sequence.

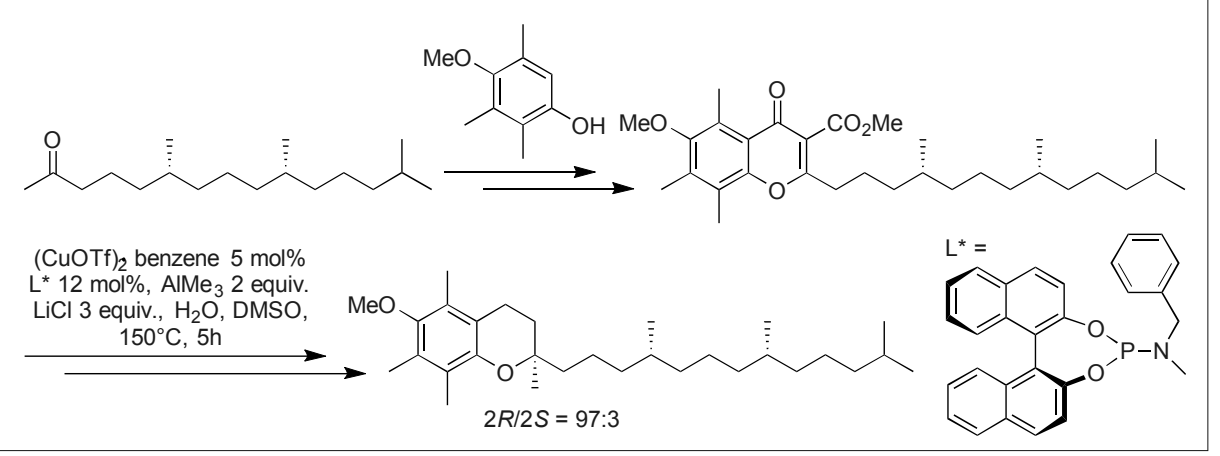

Scheme 8. Asymmetric Cu-catalyzed 1,4-addition.

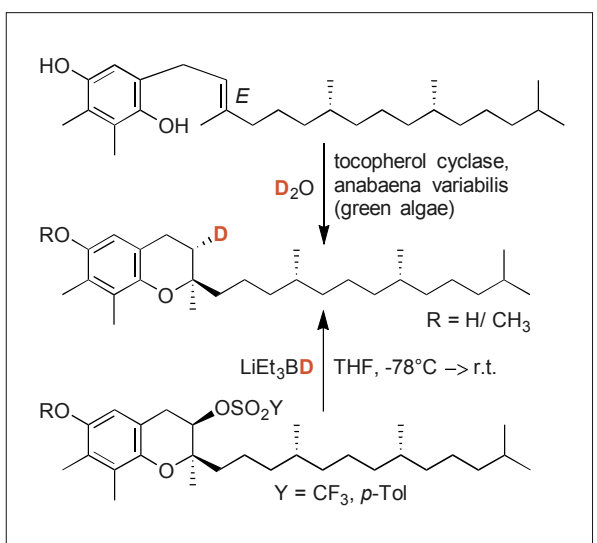

Scheme 6. Enzymatic chromanol-ring formation.

der to move towards a bio-based renewable source, we investigated a possible phenol synthesis by using Hashmi's methodology of $\mathrm{Au}(\mathrm{I})$-catalyzed arene synthesis.[23] When starting from 2,5-dimethylfuran, which is under discussion as a biofuel, ${ }^{[24]}$ we indeed found a new access to 2,3,6-trimethylphenol with $70 \%$ yield ${ }^{25]}$ (Scheme $11)$ by the gold-mediated reaction of propyne with 2,5-dimethylfuran. The reaction with acetylene gave a mixture of 2,5- and 2,4-dimethylphenols ${ }^{[26]}$ which can both, but separately, be transformed to 2,3,6TMP.

\subsection{Vitamin A - Catalytic Coupling}

Vitamin A is a lipid-soluble vitamin, which is essential for the vision process, growth, and cell functions. Technically vitamin $\mathrm{A}$ is produced by chemical synthesis based on $\beta$-ionone. In 100 years of vitamin research only three vitamin A processes have been industrialized. All production processes use stoichiometric reactions (Wittig, Julia, Grignard) which generate equimolar amounts of waste streams (Scheme 12). ${ }^{[1 \mathrm{a}, 27]}$ As an example, the new $\mathrm{C}_{15}+\mathrm{C}_{5}$ route depicted in Scheme 13 delivers the potential for avoiding stoichiometric coupling conditions and thus reducing the formation of by-products by a catalytic synthesis of vitamin A acetate. ${ }^{[28]}$

\section{5 (+)-Biotin - Asymmetric Hydrogenation}

The general production method for (+)-biotin still applied today is a multistep chemical total synthesis, for example following the Goldberg-Sternbach concept (Scheme 14).[1a] A preferred option for introducing the chirality is D-lactone (D-thiolactone) 31 by desymmetrization of the corresponding meso-anhydride (-thioanhydride) 30. In a collaboration with Solvias, a breakthrough by an enantioselective catalytic approach could be achieved in a surprisingly short period of time with a limited number of screening experiments. ${ }^{[29]}$ Ruthenium, rhodium and iridium complexes with atropisomeric 


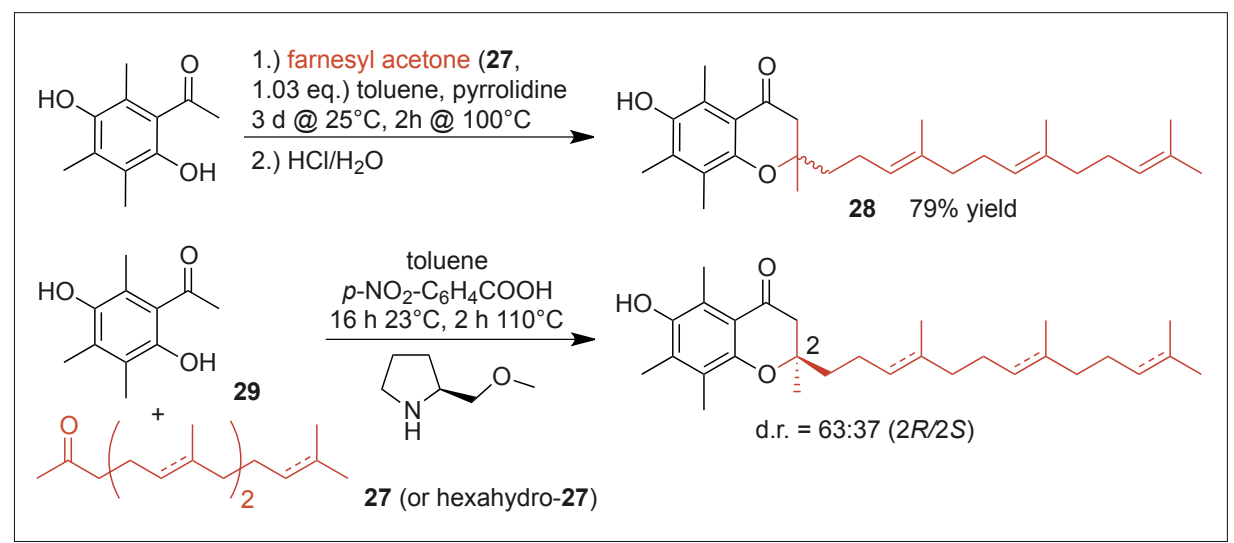

Scheme 9. Asymmetric organocatalytic condensation reaction.

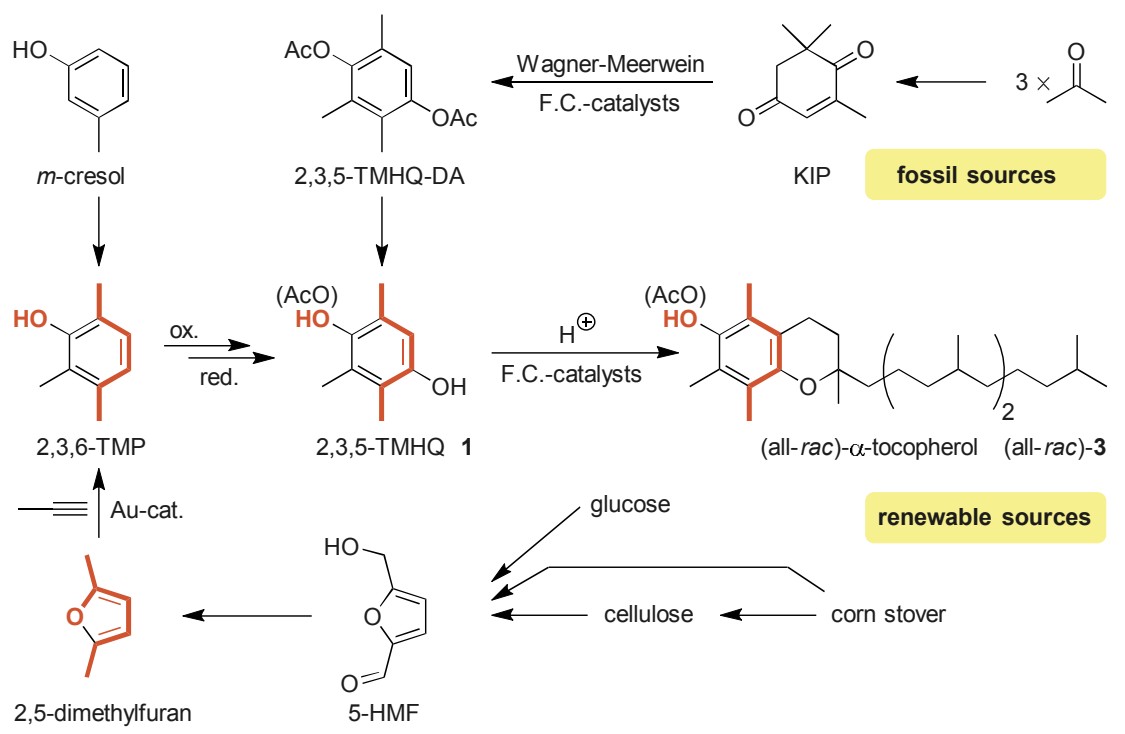

Scheme 10. Alternative access to vitamin E key building blocks.

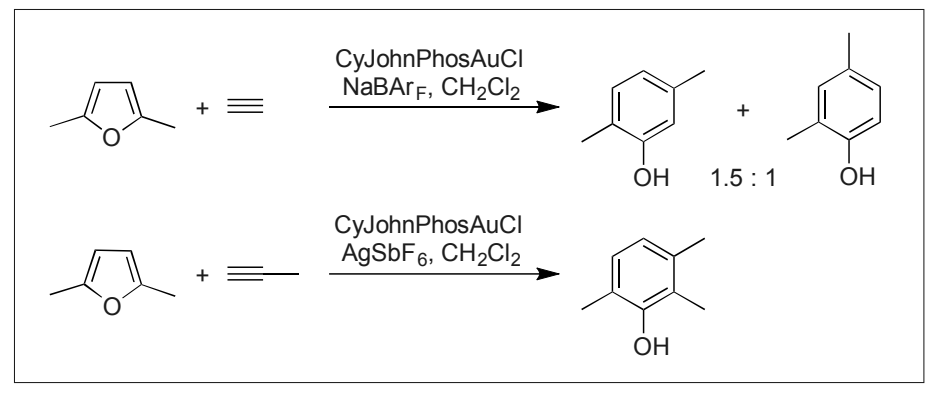

Scheme 11. Au(1)catalyzed phenol synthesis.

ligands delivered excellent results (complete conversion, ee values of $>95 \%$ ) after some optimization. Even piloting on multikilogram scale and production trials could be performed without major problems.

\section{Nutraceuticals}

Nutraceuticals are active ingredients in functional food or nutritional supplements delivering a health benefit. ${ }^{[1 b]}$ Examples of an important class of industrially produced compounds are polyphenols acting as antioxidants, such as resveratrol, hydroxyty- our studies towards a more efficient $\mathrm{CoQ}_{10}$ synthesis we focused on the metal-catalyzed allylic substitution as the key step for the coupling of protected aromatic precursors with the $\mathrm{C}_{50}$ side chain. The resulting coupling product can be deprotected and oxidized to coenzyme $\mathrm{Q}_{10}$ in good yield. In contrast to all other tested catalysts (delivering an E/Z-selectivity of $<70: 30$ and moderate yields), $\mathrm{Mo}(\mathrm{CO})_{3} \mathrm{C}_{7} \mathrm{H}_{8}$ was found to catalyze the coupling of aromatic Grignard reagents to allylic acetates in high E/Z-selectivity of $86: 14$ and good yields of $85 \%$. $^{[31]}$

\section{Acknowledgements}

I am grateful to the Swiss Industry Science Fund and the Swiss Chemical Society for the Senior Industrial Investigator Award 2017. Furthermore, I would like to thank all colleagues, i.e. peers, supervisors, co-workers, technicians, apprentices, students, postdocs, collaborators, consultants, and people from service functions for their valuable support and contributions over many years. Only a selection of names appears in the listing of references.

Received: June 12, 2018

[1] a) M. Eggersdorfer, D. Laudert, U. Létinois, T. McClymont, J. Medlock, T. Netscher, W. Bonrath, Angew. Chem. Int. Ed. 2012 51, 12960; b) M. Eggersdorfer, D. Laudert, U. Létinois, T. McClymont, J. Medlock, T. Netscher, W. Bonrath, Angew. Chem. 2012 124, 13134; c) B. Wüstenberg, R.T. Stemmler, U. Létinois, W. Bonrath, M. Hugentobler, T. Netscher, Chimia 2011, 65, 420; d) W. Bonrath, M. Eggersdorfer, T. Netscher, Catal. Today 2007, 121, 45; e) W. Bonrath, T. Netscher, Appl. Catal. A: Gen. 2005, 280, 55

[2] a) W. Bonrath, A. Haas, E. Hoppmann, T. Netscher, H. Pauling, F. Schager, A. Wildermann, Adv. Synth. Catal. 2002, 344, 37; b) T. Netscher, W. Bonrath, A. Haas, E. Hoppmann, H. Pauling, Chimia 2004, 58, 153.

[3] W. Bonrath, A. Haas, E. Hoppmann, T. Netscher, H. Pauling, EP 1134218 A1, 2001.

[4] a) U. Wietelmann, W. Bonrath, T. Netscher, H. Nöth, J.-C. Panitz, M. Wohlfahrt-Mehrens, Chem. Eur. J. 2004, 10, 2451; b) W. Bonrath, T. Netscher, U. Wietelmann, EP 1227089 A1, 2002.

[5] W. Bonrath, F. Aquino, A. Haas, S. Hoppmann, T. Netscher, F. Pace, H. Pauling, Sustainability $\mathbf{2 0 0 9}, 1,161$.

[6] For reviews see: a) T. Netscher, Vitamins and Hormones 2007, 76, 155; b) T. Netscher, 'Synthesis and production of vitamin E', in 'Lipid Synthesis and Manufacture', Ed. F. D. Gunstone, Sheffield Academic Press Ltd, Sheffield, UK, 1999, pp. 250-267; c) K.U. Baldenius, L. von dem Bussche-Hünnefeld, E. Hilgemann, P. Hoppe, R. Stürmer, in 'Ullmann's Encyclopedia of Industrial Chemistry', VCH, Weinheim, 1996, vol. A27, pp. 478-488.

[7] T. Netscher, M. Scalone, R. Schmid in 'Asymmetric Catalysis on Industrial Scale', Eds. H. U. Blaser, E. Schmidt, Wiley-VCH, 1st ed. 2003, Weinheim, pp. 71-89.

[8] a) A. Knierzinger, W. Walther, B. Weber, R.K. Müller, T. Netscher, Helv. Chim. Acta 1990, 73 , 1087; b) A. Knierzinger, W. Walther, B. Weber, T. Netscher, Chimia 1989, 43, 163. 


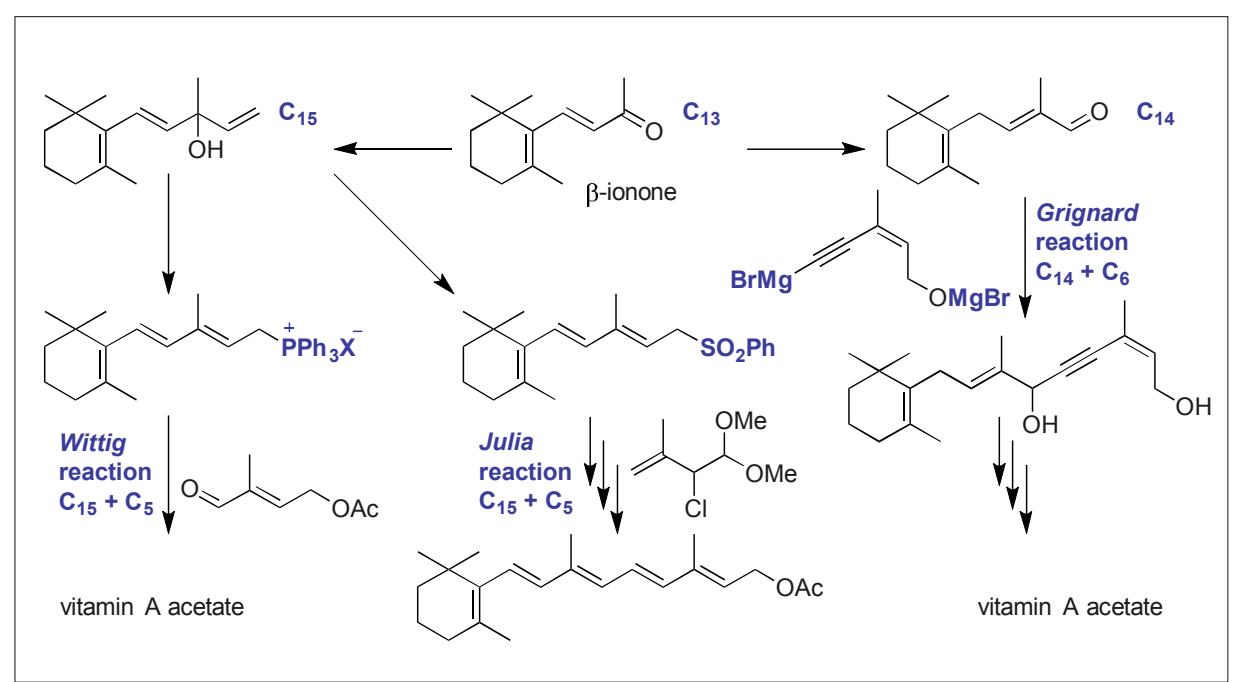

Scheme 12. Industrialized vitamin A processes.

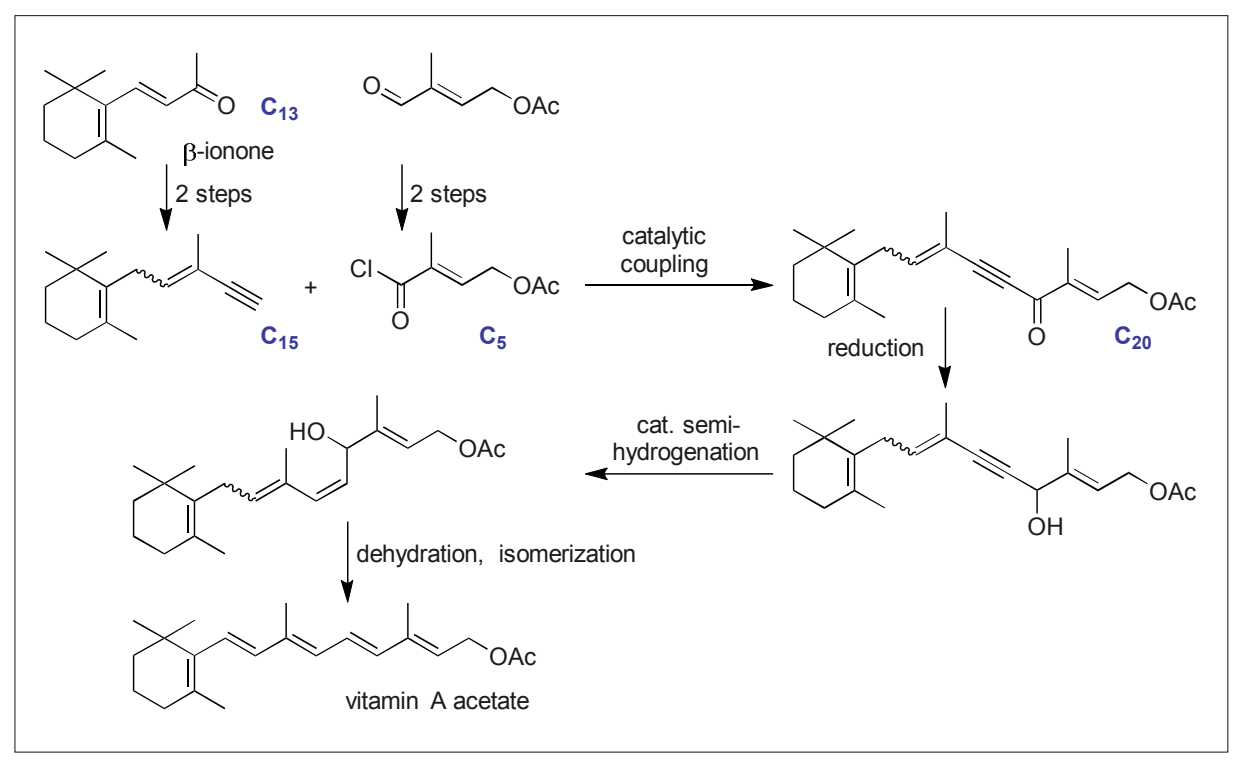

Scheme 13. Catalytic route to vitamin A acetate.

a)

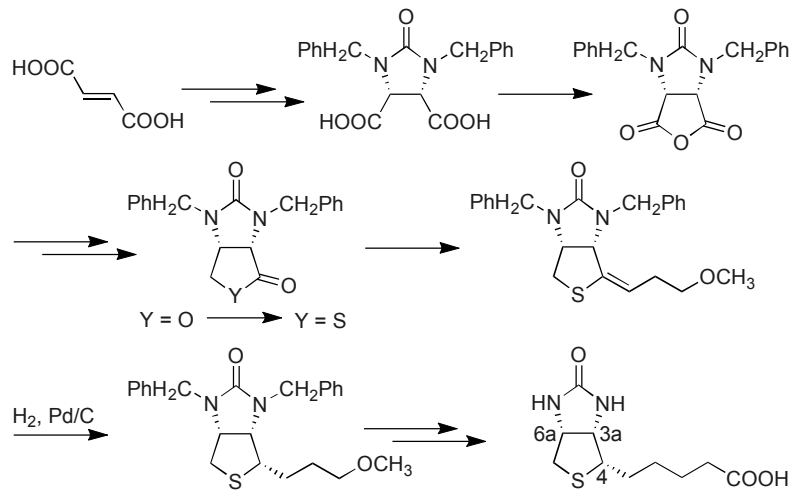

(+)-biotin

b)

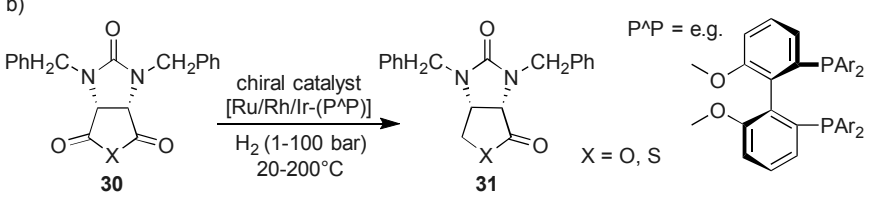

[9] T. Netscher, Chimia 1996, 50, 563.

[10] T. Netscher, 'Roche Lecture: Vitamin E: Synthesis and Stereochemistry', presented at the following institutions: Roche Basel, Switzerland, 12. Mai 1997; Institut de chimie organique, Université de Fribourg, Switzerland, June 12, 1997; Institut für Organische Chemie, Universität Basel, Switzerland, 13. Juni 1997; Organisch-Chemisches Institut, Westfälische Wilhelms-Universität Münster, Germany, 19. Juni 1997; Institut für Organische Chemie, Technische Universität Dresden, Germany, 11. Juli 1997; Faculté et centre de recherche de chimie, Université Louis Pasteur Strasbourg, France, October 10, 1997; Organisch-Chemisches Institut, Ruprecht-Karls-Universität Heidelberg, Germany, 13. Oktober 1997; Faculté des sciences, Université catholique de Louvain, Louvain-la-Neuve, Belgium, October 17, 1997; Institut für Pharmazeutische Chemie, Universität Wien, Austria, 20. Oktober 1997; Institut für Pharmazeutische Chemie, Universität Graz, Austria, 21. Oktober 1997; Chemische Institute, Leopold-FranzensUniversität Innsbruck, Austria, Österreichische Pharmazeutische Gesellschaft, 23. Oktober 1997; Organisch-chemisches Institut, Universität Zürich, Switzerland, 28. Oktober 1997; Fakultät für Chemie, Universität Konstanz, Germany, GDCh-Vortrag, 30. Oktober 1997; University Chemical Laboratory, Cambridge University, UK, November 3, 1997; Department of Chemistry, Imperial College of Science, Technology and Medicine, London, UK, November 4, 1997; Roche Discovery Welwyn, Welwyn Garden City, UK, November 5, 1997; The Dyson Perrins Laboratory, Oxford University, UK, November 6, 1997; Institut de Chimie organique de l'Université de Lausanne, BCh, Lausanne-Dorigny, Switzerland, November 12, 1997; Département de Chimie Organique, Université de Genève, Switzerland, November 13, 1997; Laboratorium für Organische Chemie, Eidgenössisch-Technische Hochschule Zürich, Switzerland, 24. November 1997; Departement für Chemie und Biochemie, Universität Bern, Switzerland, November 26, 1997; Institut für Organische Chemie, Rheinisch-Westfälische Technische Hochschule Aachen, Germany, 28. November 1997; Fachbereich Chemie, Philipps-Universität Marburg, Germany, GDCh Ortsverband Marburg, 12. Dezember 1997; Chemisches Laboratorium, Albert-LudwigsUniversität Freiburg im Breisgau, Germany, Organisch-Chemisches Kolloquium, 15. Dezember 1997; Institut de Chimie, Université de Neuchâtel, Switzerland, January 7, 1998; Max-Planck-Institut für Kohlenforschung, Mülheim a.d. Ruhr, Germany, 20. Januar 1998.

[11] See also ref. [12]: SCS Fall Meeting 2015 lectures, Chimia 2015, 69, 456.

[12] M. Scalone, 'The Importance of Catalysis in the Synthesis of Active Pharmaceutical Ingredients - A personal retrospective', KGF-SCS Senior Industrial Science Award Lecture presented at the SCS Fall Meeting on 4 Sept. 2015 in Lausanne; the slide has been re-drawn by T.N. in order to provide a uniform appearance in this article.

[13] See also: R. Schmid, 'Homogeneous Catalysis with Metal Complexes in a Pharmaceuticals' and Vitamins' Company: Why, What for, and Where to Go?' Chimia 1996, 50, 110.

[14] A. Wang, B. Wüstenberg, A. Pfaltz, Angew. Chem. Int. Ed. 2008, 47, 2298.

[15] S. Bell, B. Wüstenberg, S. Kaiser, F. Menges, T. Netscher, A. Pfaltz, Science 2006, 311, 642.

[16] a) T. Netscher, R.K. Müller, H. Schneider, E.-i. Negishi, Int. Electron. Conf. Synth. Org. Chem. 2011, a69/1; b) E.-i. Negishi, Pure Appl. Chem. 1981, 53, 2333; c) E.-i. Negishi, D.E. Van Horn, T. Yoshida, J. Am. Chem. Soc. 1985, 107, 6639; 


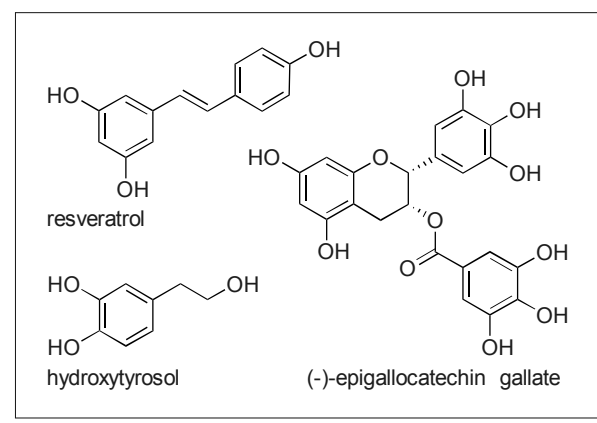

Fig. 5. Examples of nutraceuticals.

d) F. Zeng, E.-i. Negishi, Org. Lett. 2001, 3, 719 .

[17] See e.g.: a) W. Bonrath, T. Netscher, J. A. Medlock, R. T. Stemmler, J. Tschumi, G. K. M. Verzijl, A. H. M. de Vries, WO 2014096065 A1, 2014; b) W. Bonrath, T. Netscher, J. A. Medlock, G. K. M. Verzijl, A. H. M. De Vries, US 9,561,989 B2, 2017.

[18] a) A. Stocker, T. Netscher, A. Rüttimann, R. K. Müller, H. Schneider, L. J. Todaro, G. Derungs, W.-D. Woggon, Helv. Chim. Acta 1994, 77, 1721; b) A. Stocker, A. Rüttimann, W.-D. Woggon, Helv. Chim. Acta 1993, 76, 1729; c) A. Stocker, H. Fretz, H. Frick, A. Rüttimann, W.-D. Woggon, Bioorg. Med. Chem. 1996, 4 , 1129.

[19] a) C. Rein, P. Demel, R. A. Outten, T. Netscher, B. Breit, Angew. Chem. Int. Ed. 2007, 46, 8670; b) C. Rein, P. Demel, R. A. Outten, T. Netscher, B. Breit, Angew. Chem. 2007, 119, 8824

[20] A. O. Termath, H. Sebode, W. Schlundt, R. T. Stemmler, T. Netscher, W. Bonrath, H.-G. Schmalz, Chem. Eur. J. 2014, 20, 12051.

[21] a) H. J. Kabbe, H. Heitzer, Synthesis 1978, 888; b) H.-J. Kabbe, A. Widdig, Angew. Chem. 1982 94, 254; c) H.-J. Kabbe, A. Widdig, Angew. Chem. Int. Ed. Engl. 1982, 21, 247.

[22] a) U. Letinois, T. Netscher, WO 2015001029 2015; b) U. Letinois, T. Netscher, S. Ackermann, WO 2015001030, 2015; c) U. Letinois, W. Bonrath, J. Medlock, T. Netscher, WO 2015001027, 2015.

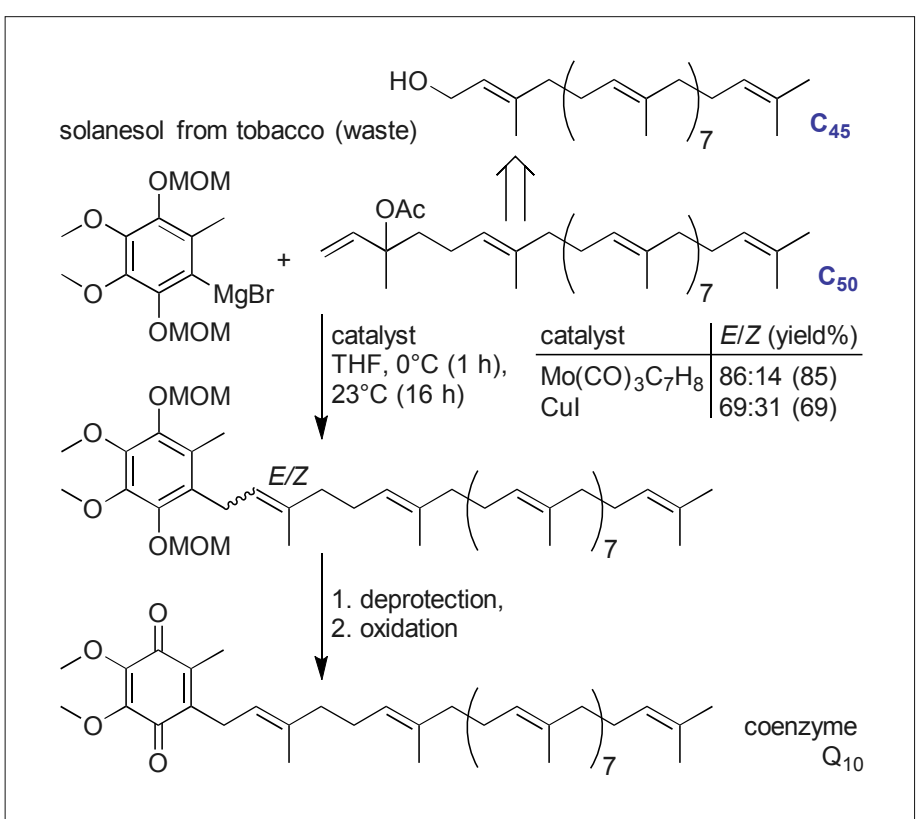

Scheme 15.

Chemical synthesis of coenzyme $Q$ by allylic substitution.
[23] A. S. K. Hashmi, M. C. Blanco, E. Kurpejović, W. Frey, J. W. Bats, Adv. Synth. Catal. 2006, 348, 709 .

[24] a) Y. Qian, L. Zhu, Y. Wang, X. Lu, Renew. Sust. Energy Rev. 2015, 41, 633; b) J. Chen, Y. Guo, J. Chen, L. Song, L. Chen, ChemCatChem 2014, 6, 3174 .

[25] W. Bonrath, U. Letinois, T. Netscher, WO 2015110654, 2015.

[26] W. Bonrath, U. Letinois, T. Netscher, WO 2015110655, 2015.

[27] For reviews see: a) O. Isler, Pure Appl. Chem. 1979, 51, 447; b) M. John, W. Hähnlein in 'Ullmann's Enzyclopedia of Industrial Chemistry', vol. A27, 1996, pp. 453-469, VCH, Weinheim.

[28] J. Schütz, W. Bonrath, C. Eggertswyler, J Medlock, T. Netscher, B. Wüstenberg, presented at the $20^{\text {th }}$ European Symposium on Organic Chemistry (ESOC 2017), Cologne, Germany, 2-6 July 2017, Poster SY078.
[29] a) W. Bonrath, R. Karge, T. Netscher, F. Roessler, F. Spindler, Chimia 2009, 63, 265; b) W. Bonrath, R. Karge, T. Netscher, F. Roessler, F. Spindler, in 'Asymmetric Catalysis on Industrial Scale: Challenges, Approaches, and Solutions', Eds. H.-U. Blaser, H.-J. Federsel, $2^{\text {nd }}$ ed., 2010, pp. 27-39, Wiley-VCH, Weinheim.

[30] a) M. Kanazawa, T. Takahashi, in 'Biochemical and Clinical Aspects of Coenzyme Q10', Eds. Y. Yamamura, K. Folkers, Y. Ito, Elsevier, Amsterdam, The Netherlands, vol. III, p. 31, 1981; b) B. H. Lipshutz, A. Lower, V. Berl, K. Schein, F. Wetterich, Org. Lett. 2005, 7, 4095.

[31] B. Wüstenberg, M. Stettler, A. Radspieler, W. Bonrath, M. Hugentobler, T. Netscher, presented at the 41. Jahrestreffen Deutscher Katalytiker, 27-29 February 2008, Weimar (D), P 27. 